\title{
CORRECTION
}

View Article Online

View Journal I View Issue

Check for updates

Cite this: Mater. Chem. Front., 2020, 4, 676

DOI: $10.1039 / \mathrm{c} 9 \mathrm{qm} 90060 \mathrm{~h}$

rsc.li/frontiers-materials

\section{Correction: Ordered mesoporous carbon and its applications for electrochemical energy storage and conversion}

Ali Eftekhari*a and Zhaoyang Fan ${ }^{b}$

Correction for 'Ordered mesoporous carbon and its applications for electrochemical energy storage and conversion' by Ali Eftekhari and Zhaoyang Fan, Mater. Chem. Front., 2017, 1, 1001-1027.

The Royal Society of Chemistry has been notified by Ulster University that Ali Eftekhari was not authorised to use Ulster University as an affiliation. The affiliation to Ulster University has therefore been removed at the institution's request.

The Royal Society of Chemistry apologises for these errors and any consequent inconvenience to authors and readers.

\footnotetext{
${ }^{a}$ School of Chemistry and Chemical Engineering, Queen's University Belfast, Stranmillis Road, Belfast BT9 5AG, UK. E-mail: eftekhari@elchem.org

${ }^{b}$ Department of Electrical \& Computer Engineering and Nano Tech Center, Texas Tech University, Lubbock, Texas 79409, USA. E-mail: zhaoyang:fan@ttu.edu
} 